\title{
Serum ferritin and high sensitivity C-reactive protein are associated with metabolic syndrome in Japanese men and women
}

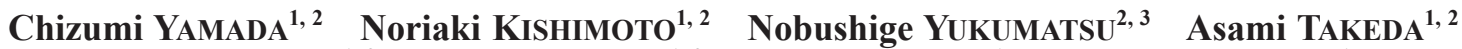 \\ Tamae OGATA $^{1,2}$ Emiko KIKUCHI $^{1,2}$ Emiko KUROdA $^{1}$ Shigeyuki Motegi $^{1}$ \\ Naoaki ISHII ${ }^{2,3}$ Yasuhiro NISHIZAKI ${ }^{1,2,3}$ \\ ${ }^{I}$ Tokai University Tokyo Hospital \\ ${ }^{2}$ Department of Clinical Health Science, Tokai University School of Medicine \\ ${ }^{3}$ Life Care Center, Graduate School of Medicine, Tokai University
}

\begin{abstract}
Objective Ferritin is involved in the occurrence of oxidative stress and regulation of adiponectin, both of which can modulate metabolic syndrome (MetS). To investigate the association of ferritin with MetS in Japanese, a cross-sectional study was conducted involving 324 men and 340 women who underwent anti-aging health checks at Tokai University Tokyo Hospital.

Methods The MetS criteria of the Japanese Society of Internal Medicine was used and the levels of serum ferritin and high sensitivity C-reactive protein (hsCRP) were compared with or without MetS-related abnormalities (abdominal obesity, waist circumference $\geq 85 \mathrm{~cm}$ in men and $\geq 90 \mathrm{~cm}$ in women; hypertension, systolic $\mathrm{BP} \geq 130$ and/or diastolic $\mathrm{BP} \geq$ $85 \mathrm{mmHg}$; hyperglycemia, fasting glucose $\geq 110 \mathrm{mg} / \mathrm{dL}$; and dyslipidemia, triglycerides $\geq 150 \mathrm{mg} / \mathrm{dL}$ and/or $\mathrm{HDL}-\mathrm{C}<$ $40 \mathrm{mg} / \mathrm{dL}$ ).

Resufts Ferritin levels were significantly higher in the subjects with hyperglycemia and dyslipidemia in both men and women, and in those with abdominal obesity in women. HsCRP levels were significantly higher in the subjects with abdominal obesity in both sexes, and in those with hypertension in men. Serum ferritin increased in proportion to the number of MetS components and was significantly higher in MetS subjects than in non-MetS counterparts in both men and women, although these results were not obtained regarding hsCRP.

Conclusion Ferritin is not considered inferior compared with the well-known marker hsCRP with respect to the association with MetS. High serum ferritin concentrations could potentially be used as a biomarker for MetS as well as hsCRP. (HEP. 2016; 43: 511-517.)

Key words Ferritin, high sensitivity C-reactive protein (hsCRP), metabolic syndrome (MetS), anti-aging health checkup system
\end{abstract}

\section{INTRODUCTION}

Ferritin is a protein commonly used as a biomarker of body iron stores, and is also induced by inflammation. Increasing evidence has suggested that elevated serum ferritin levels are associated with increased risk of type 2 diabetes $^{1-5)}$, hypertension ${ }^{6}$, dyslipidemia $^{7,8)}$ and central adiposity ${ }^{9}$. Not only single cardiovascular risk factors, but also a positive relationship between high ferritin levels and MetS has been demonstrated by a meta-analysis $^{10)}$. According to Abril-Ulloa et al., the pooled odds ratio for MetS comparing the highest and the lowest category of ferritin levels was 1.73 (95\% CI: 1.54, 1.95). However, this study did not include Japanese people and the criteria used for MetS diagnosis were mainly those of the National Cholesterol Education Program's Adults Treatment Panel III (NCEP ATP III) ${ }^{11)}$.

The mechanisms of the effect of elevated ferritin on metabolic

Received: February 12, 2016, Accepted: May 16, 2016

Corresponding author: Prof. Yasuhiro Nishizaki

${ }^{1}$ Address; Tokai University Tokyo Hospital

1-2-5 Yoyogi, Shibuya-ku, Tokyo 153-0065, Japan

TEL: +81-3-3370-2321, FAX: +81-3-5354-5366

E-mail: y-nishizaki@tokai.ac.jp disorders are not fully understood. Chronic inflammation in adipose tissue plays an important part in the pathophysiology of metabolic syndrome $(\mathrm{MetS})^{12)}$, and increased ferritin may reflect the inflammatory component of MetS. It was recently reported that iron excess decreases adiponectin levels ${ }^{13}$, causing insulin resistance and glucose intolerance, which can well modulate the MetS condition.

To investigate the association of ferritin with MetS in Japanese, we carried out a cross-sectional study involving 324 men and 340 women who underwent anti-aging health checks at Tokai University Tokyo Hospital. The MetS criteria of the Japanese Society of Internal Medicine were used and the levels of serum ferritin and high sensitivity C-reactive protein (hsCRP), which is well known as a useful marker for predicting cardiovascular events in MetS, were compared with or without MetSrelated abnormalities.

\section{SUBJECTS AND METHODS}

\section{Subjects}

664 subjects (324 men and 340 women) aged between 26 and 86 years who first underwent anti-aging health checks at Tokai University Tokyo Hospital were enrolled. The surveillance period 
was from June 2006 to December 2013. All subjects gave written informed consent to the use of their health records for analysis. This study was approved by the Ethics Committee of Tokai University, and was conducted in accordance with the Declaration of Helsinki.

\section{Measurements}

Anthropometric measurements were performed and blood samples were obtained after overnight fasting. Of the measurements included in the anti-aging health check examinations ${ }^{15}$, the following parameters were used for analysis: body mass index (BMI), waist circumference (WC), systolic and diastolic blood pressure (BP), fasting glucose, HDL-C, triglycerides, serum ferritin and hsCRP. Height and weight were measured in the standing position, and BMI was calculated as weight $/$ height $^{2}\left(\mathrm{~kg} / \mathrm{m}^{2}\right)$. WC was assessed at the end of expiration by measuring the minimum circumference at the level of the umbilicus. BP was measured in the sitting position. The value for HDL-C and triglycerides were determined enzymatically. Serum level of ferritin was measured by the latex agglutination method. HsCRP concentration was measured by turbidimetric immunoassay.

\section{Statistical analysis}

Data is expressed as mean \pm standard deviation (SD). SPSS Statistics (Version 22.0; SPSS Inc.) was used for the statistical analyses. Pearson's correlation coefficient was calculated as a measure of association between serum ferritin and the clinical parameters. The levels of serum ferritin and hsCRP were compared with or without MetS-related abnormalities (MetS components). MetS components were defined as follows: abdominal obesity, WC $\geq 85 \mathrm{~cm}$ in men and $\geq 90 \mathrm{~cm}$ in women; hypertension, systolic $\mathrm{BP} \geq 130$ and/or diastolic $\mathrm{BP} \geq 85 \mathrm{mmHg}$; hyperglycemia, fasting glucose $\geq 110 \mathrm{mg} / \mathrm{dL}$; and dyslipidemia, triglycerides $\geq 150 \mathrm{mg} / \mathrm{dL}$ and/or HDL-C $<40 \mathrm{mg} / \mathrm{dL}$. MetS was diagnosed if subjects had abdominal obesity plus at least two of the following MetS components: hypertension, hyperglycemia and dyslipidemia according to the definition by the Japanese Society of Internal Medicine ${ }^{14)}$. Student's $t$-test was used for comparisons between the two groups. Statistical significance for comparisons of ferritin and hsCRP values among the groups with different numbers of components was determined using analysis of variance (ANOVA) followed by Dunnett's multiple compari- son test by comparison with a zero-component group. A value of $p<0.05$ was considered significant.

\section{RESULTS}

The clinical characteristics of the subjects are shown in Table 1. The study subjects consisted of 324 men and 340 women. The mean age was $62.9 \pm 11.0$ for men and $61.2 \pm 11.0$ for women. The average serum ferritin level was higher in men (179.9 \pm $118.4 \mathrm{ng} / \mathrm{mL})$ than in women $(82.4 \pm 63.8 \mathrm{ng} / \mathrm{mL})$. The subjects were not obese on average (BMI $23.6 \pm 4.3 \mathrm{~kg} / \mathrm{m}^{2}$ for men and $21.7 \pm 4.6 \mathrm{~kg} / \mathrm{m}^{2}$ for women), and the mean BP, fasting glucose, HDL-C, triglycerides and hsCRP values were within the normal ranges.

The correlations between serum ferritin and MetS-related parameters are shown in Table 2. Serum ferritin was significantly positively correlated with TG and hsCRP, and negatively correlated with HDL-C in men. In women, age, BMI, WC, systolic and diastolic BP, glucose and TG showed a significantly positive correlation, and HDL-C showed a significantly negative correlation with ferritin.

Next, serum ferritin and hsCRP levels were compared with or

Table 1 Background characteristics of the study subjects

\begin{tabular}{lcc}
\hline & Men & Women \\
\hline No. of subjects & 324 & 340 \\
Age (years) & $62.9 \pm 11.0$ & $61.2 \pm 11.0$ \\
Ferritin $(\mathrm{ng} / \mathrm{mL})$ & $179.9 \pm 118.4$ & $82.4 \pm 63.6$ \\
BMI $\left(\mathrm{kg} / \mathrm{m}^{2}\right)$ & $23.6 \pm 4.3$ & $21.7 \pm 4.6$ \\
Waist circumference $(\mathrm{cm})$ & $84.9 \pm 9.9$ & $78.5 \pm 11.1$ \\
Systolic BP $(\mathrm{mmHg})$ & $127.9 \pm 17.0$ & $120.9 \pm 18.5$ \\
Diastolic BP $(\mathrm{mmHg})$ & $76.3 \pm 10.6$ & $68.9 \pm 10.4$ \\
Fasting glucose $(\mathrm{mg} / \mathrm{dL})$ & $103.0 \pm 17.0$ & $95.8 \pm 16.3$ \\
HDL-C $(\mathrm{mg} / \mathrm{dL})$ & $57.8 \pm 13.9$ & $71.5 \pm 15.3$ \\
Triglyceride $(\mathrm{mg} / \mathrm{dL})$ & $119.4 \pm 72.5$ & $93.9 \pm 49.2$ \\
hsCRP $(\mathrm{ng} / \mathrm{mL})$ & $0.129 \pm 0.431$ & $0.059 \pm 0.126$ \\
\hline
\end{tabular}

Data are mean \pm SD.

BMI, body mass index; BP, blood pressure; HDL-C, high-density lipoprotein cholesterol; hsCRP, high-sensitivity C-reactive protein

Table 2 Correlations between ferritin and MetS-related parameters

\begin{tabular}{lrccr}
\hline & \multicolumn{3}{c}{ Men } & \multicolumn{1}{c}{ Women } \\
\cline { 2 - 5 } & $r$ & $p$ & \multicolumn{1}{c}{$r$} & \multicolumn{1}{c}{$p$} \\
\hline Age & -0.056 & 0.315 & 0.202 & $<0.001$ \\
BMI & 0.027 & 0.627 & 0.133 & 0.015 \\
Waist circumference & 0.122 & 0.029 & 0.244 & $<0.001$ \\
Systolic BP & -0.040 & 0.474 & 0.151 & 0.006 \\
Diastolic BP & 0.060 & 0.285 & 0.141 & 0.010 \\
Fasting glucose & 0.082 & 0.140 & 0.183 & 0.001 \\
Triglyceride & 0.170 & 0.002 & 0.170 & 0.002 \\
HDL-C & -0.147 & 0.008 & -0.155 & 0.004 \\
hsCRP & 0.135 & 0.015 & 0.048 & 0.380 \\
\hline
\end{tabular}


without MetS-related abnormalities. Compared with the normal group, the group with abdominal obesity showed significantly higher ferritin levels in women, and significantly higher hsCRP levels in both sexes (Figure 1). The male hypertensive group showed significantly higher hsCRP levels than the normotensive counterparts (Figure 2). The hyperglycemic group showed sig- nificantly higher ferritin levels compared with the normoglycemic group in both men and women, while there was no significant difference in hsCRP levels between those two groups (Figure 3). The group with dyslipidemia also showed significantly higher ferritin levels, but not hsCRP, than those of the group without dyslipidemia in both sexes (Figure 4).

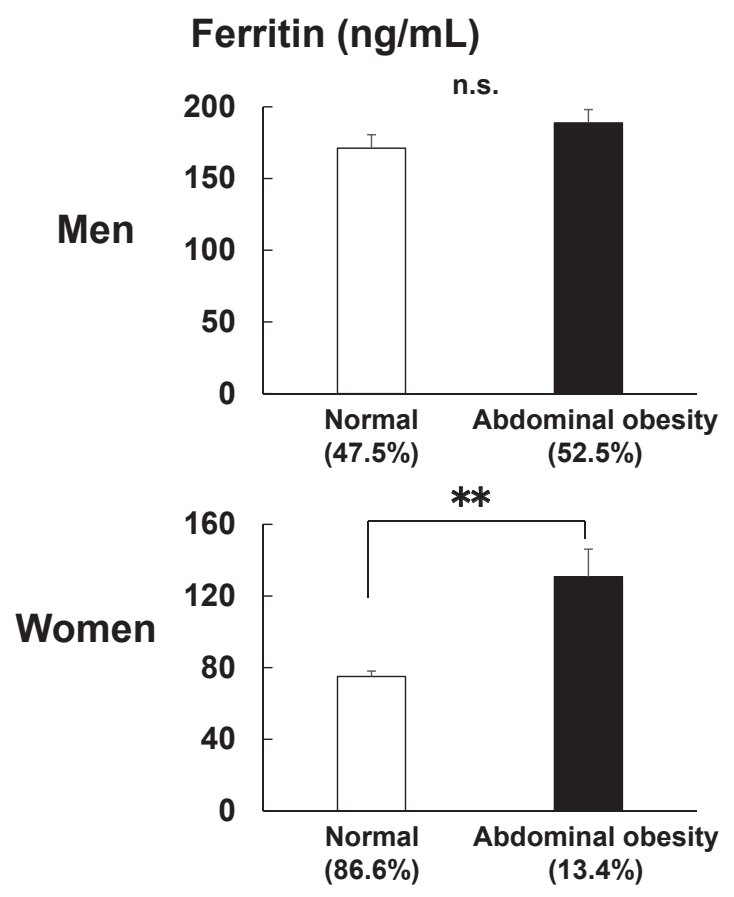

\section{hsCRP (mg/dL)}
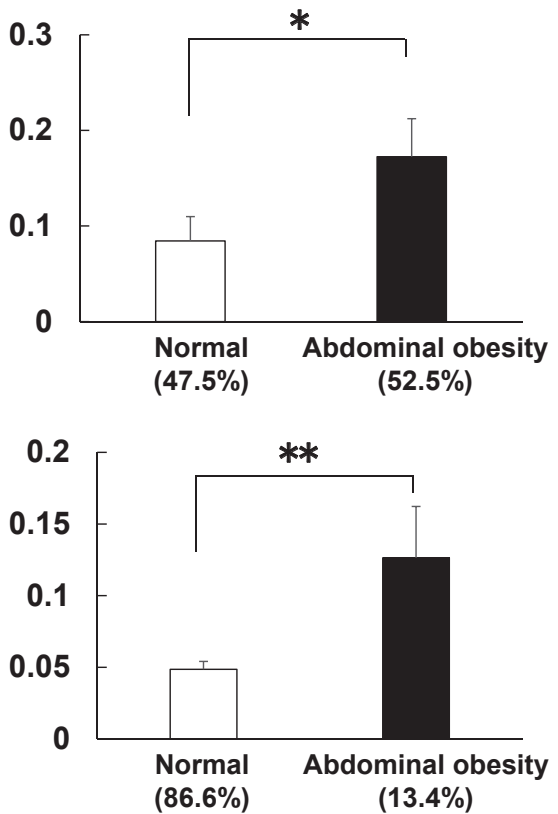

Fig. 1 Comparison of ferritin and hSCPR levels by with or without abdominal obesity. Abdominal obesity: Waist circumference men $\geq 85 \mathrm{~cm}$, women $\geq 90 \mathrm{~cm}, *: p<0.05,{ }^{* *}: p<0.01$ (t-test)

\section{Ferritin (ng/mL)}
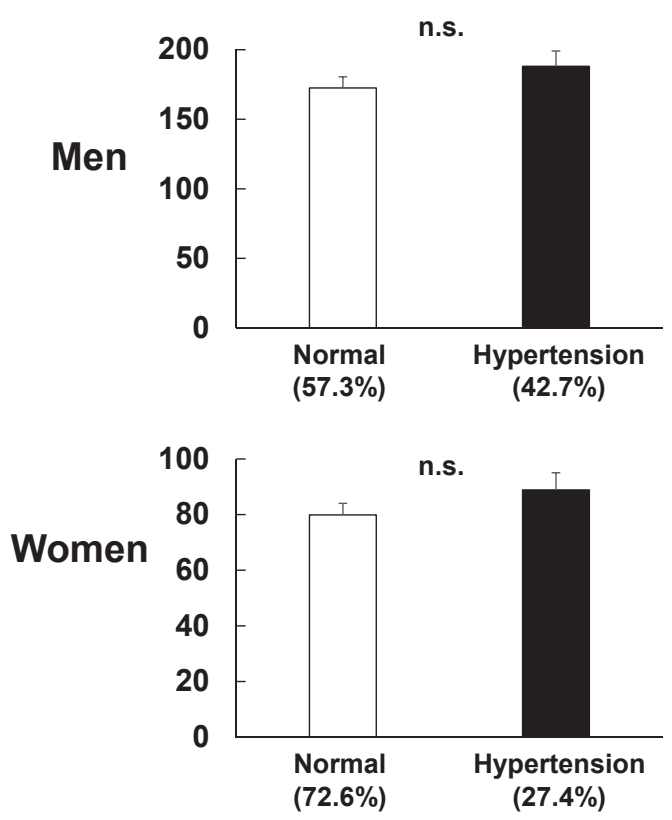

hsCRP (mg/dL)
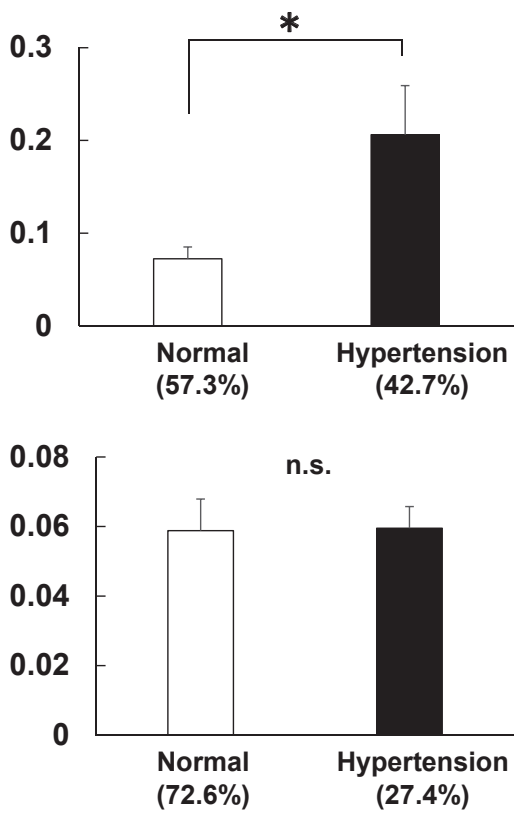

Fig. 2 Comparison of ferritin and hSCPR levels by with or without hypertension. Hypertension: Systolic BP $\geq 130$ and/or diastolic BP $\geq 85 \mathrm{mmHg}, *: p<0.05$ (t-test) 


\section{Ferritin $(\mathrm{ng} / \mathrm{mL})$}
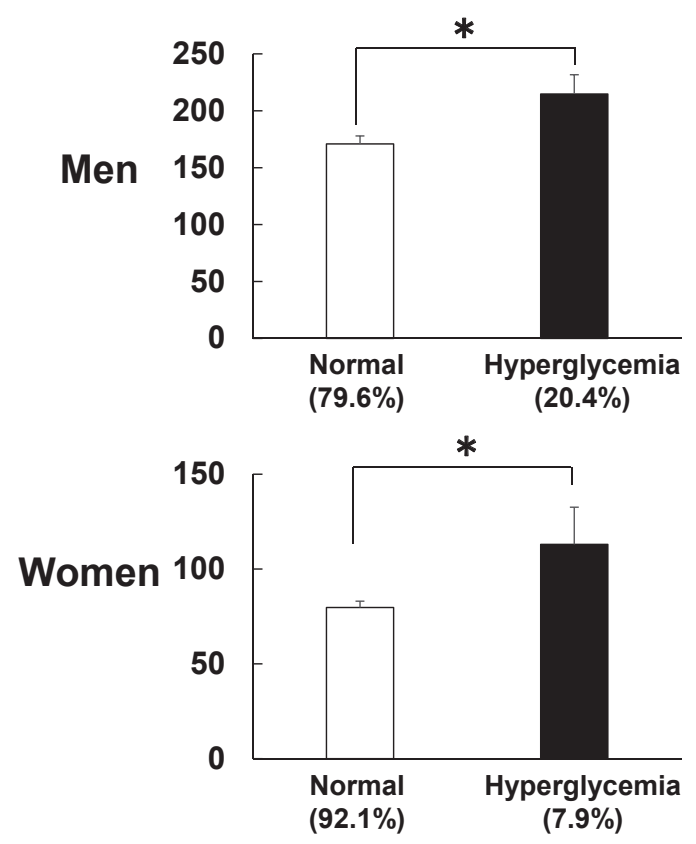

\section{hsCRP (mg/dL)}
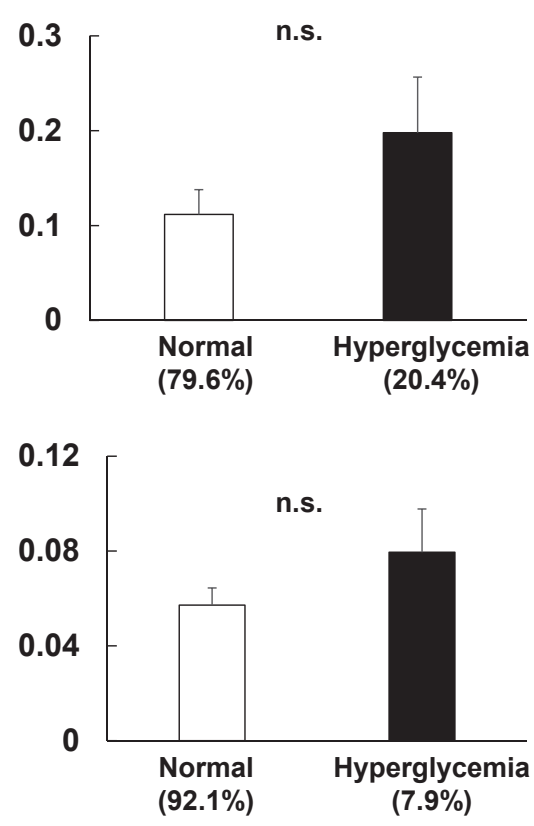

Fig. 3 Comparison of ferritin and hSCPR levels by with or without hyperglycemia. Hyperglycemia: Fasting glucose $\geq 110 \mathrm{mg} / \mathrm{dL}, *: p<0.05$ ( $t$-test)

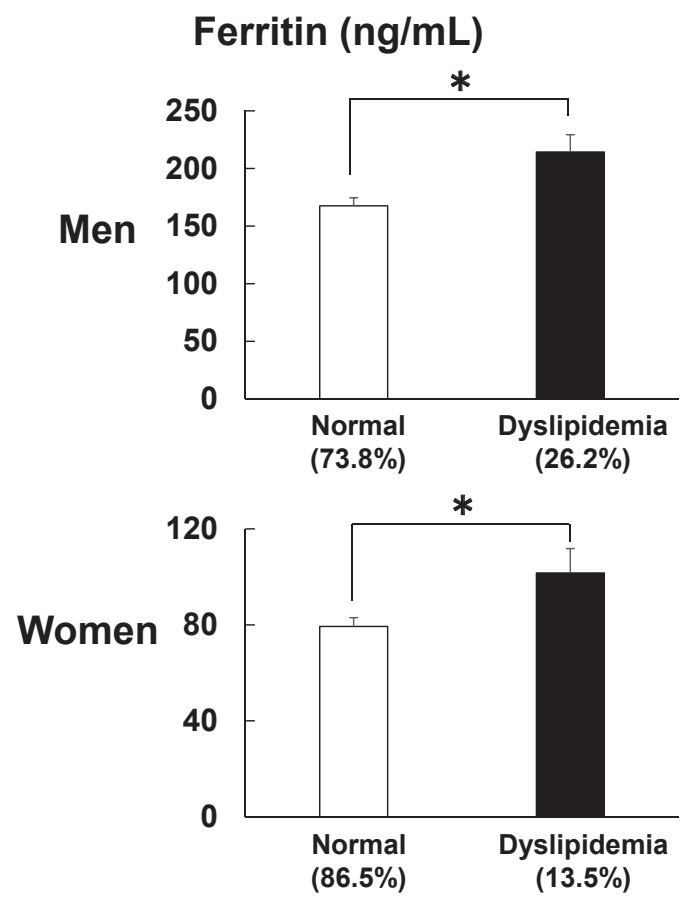

\section{hsCRP (mg/dL)}
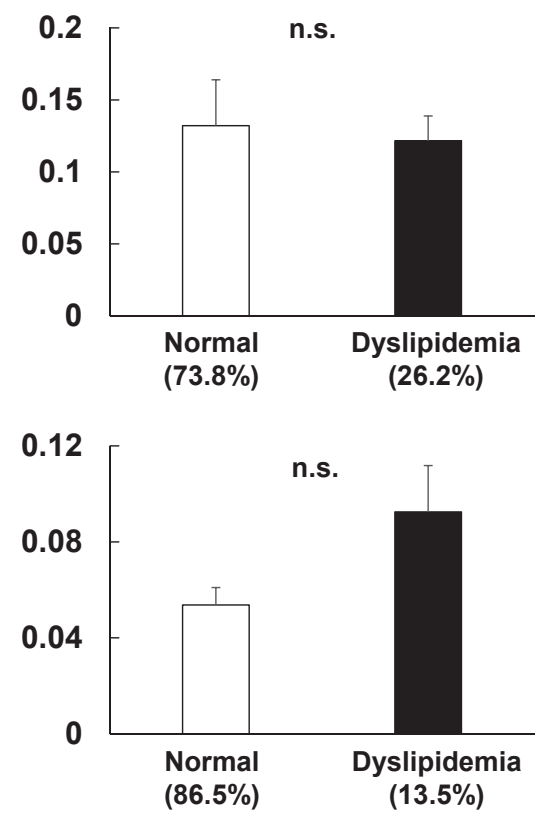

Fig. 4 Comparison of ferritin and hSCPR levels by with or without dyslipidemia.

Dyslipidemia: TG $\geq 150 \mathrm{mg} / \mathrm{dL}$ and/or HDL-C $<40 \mathrm{mg} / \mathrm{dL},{ }^{*}: p<0.05,{ }^{* *}: p<0.01$ (t-test)

To investigate whether serum ferritin increased in proportion to the severity of MetS, ferritin levels were compared stratified by the numbers of the four MetS components (abdominal obesity, hypertension, hyperglycemia and dyslipidemia). In men, serum ferritin levels increased with increasing number of components, and there was a significant difference between the zero-compo- nent group and the four-component group (Figure 5). Although there were no women with four components, statistical differences were observed in the one-, two- and three-component groups compared with the zero-component group (Figure 5). HsCRP seemed to increase with increasing number of components, though it failed to reach statistical significance in both men 

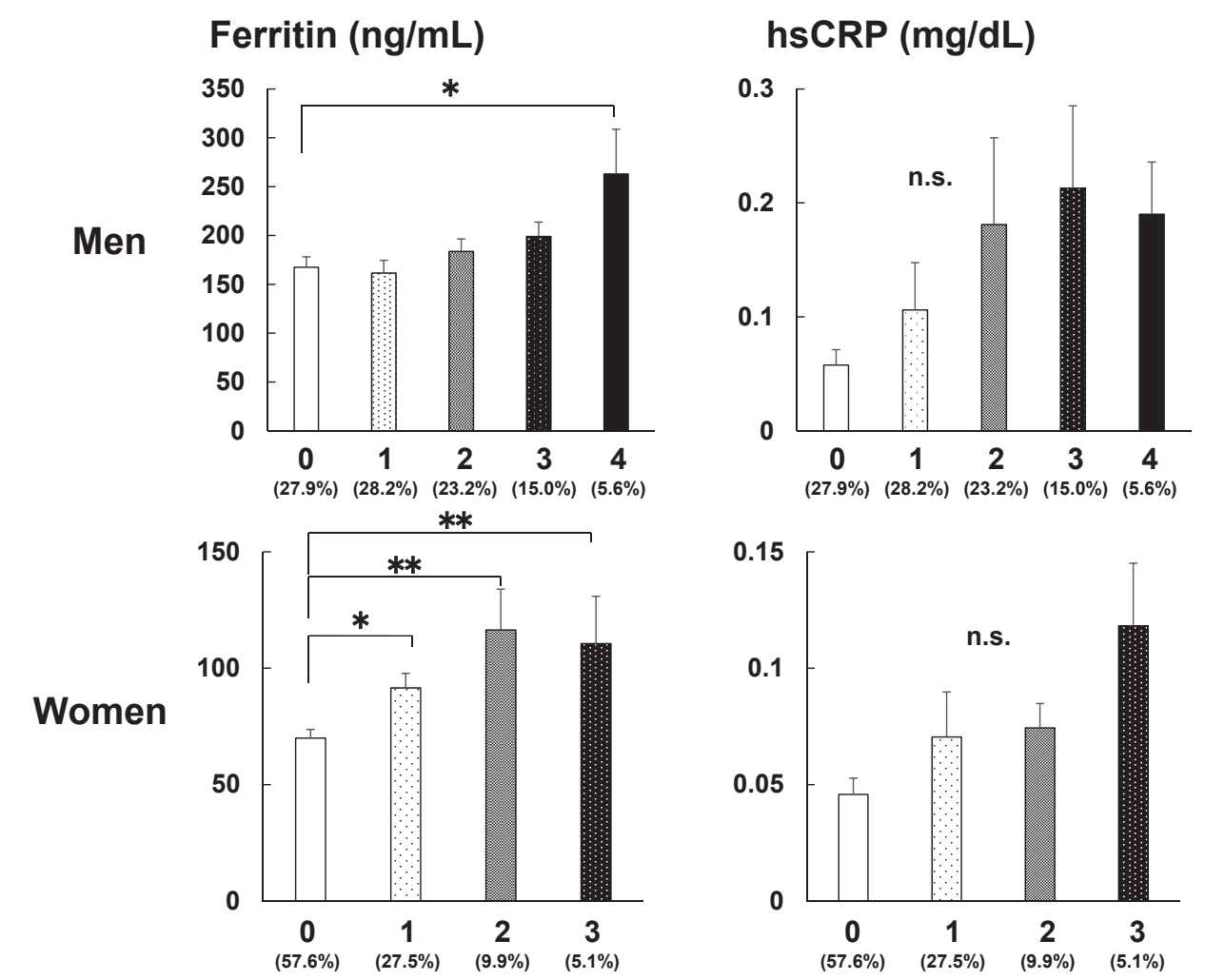

Fig. 5 Comparison of ferritin and hSCPR levels stratified by the number of MetS components.

$*: p<0.05, * *: p<0.01$ (ANOVA with Dunnett's multiple comparison test)

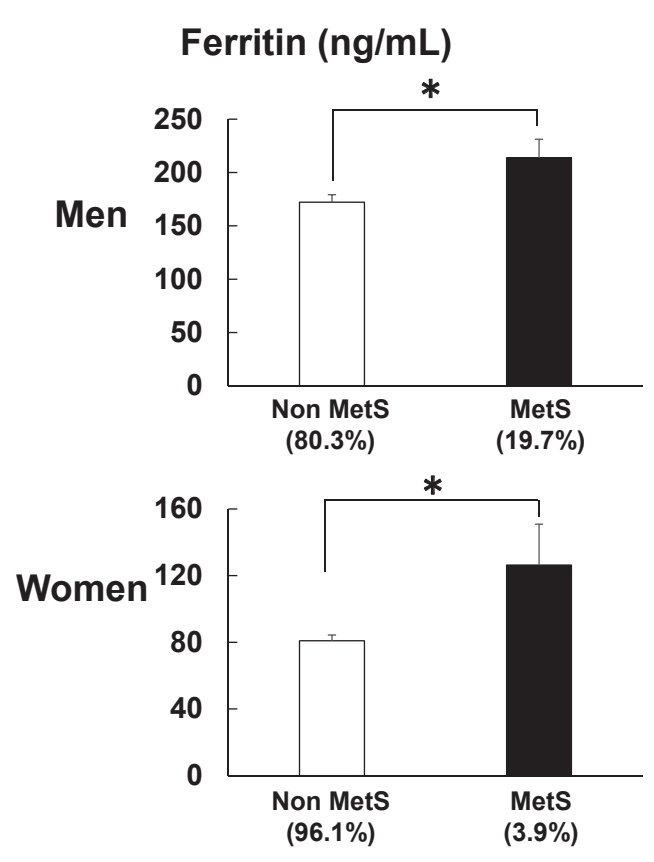

\section{hsCRP (mg/dL)}
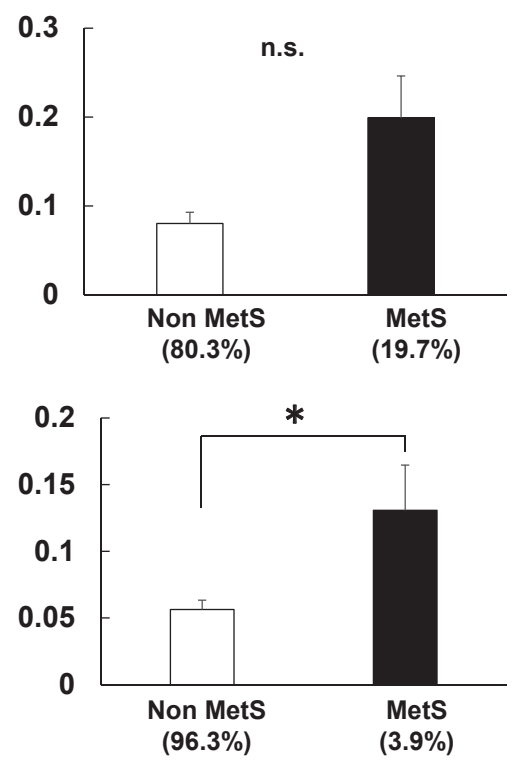

Fig. 6 Comparison of ferritin and hSCPR levels by with or without MetS.

$*: p<0.05, * *: p<0.01$ ( $t$-test)

and women (Figure 5). We further compared serum ferritin and hsCRP levels with or without MetS (Figure 6). The prevalence of MetS was $19.7 \%$ in men and $3.9 \%$ in women. It was found that ferritin, but not hsCRP, was significantly higher in MetS subjects (average ferritin values, $172.2 \pm 112.7 \mathrm{ng} / \mathrm{mL}$ for men and $80.9 \pm$
$62.2 \mathrm{ng} / \mathrm{mL}$ for women) than in non-MetS counterparts (average ferritin values, $213.8 \pm 137.6 \mathrm{ng} / \mathrm{mL}$ for men and $126.3 \pm 88.4$ $\mathrm{ng} / \mathrm{mL}$ for women) in both men and women. 


\section{DISCUSSION}

In the present study, the association between serum ferritin and MetS-related abnormalities was examined in 324 men and 340 women, and compared with that of between hsCRP and MetS. We identified that ferritin levels were significantly higher in the subjects with hyperglycemia and dyslipidemia in both men and women, and in those with abdominal obesity in women. On the other hand, hsCRP levels were significantly higher in the subjects with abdominal obesity in both sexes, and in those with hypertension in men. Serum ferritin increased in proportion to the number of MetS components and was significantly higher in MetS subjects than in non-MetS counterparts in both men and women, though these results were not obtained regarding hsCRP.

The first diagnostic criteria for MetS were proposed by the World Health Organization (WHO) in $1998^{16}$. Since then, several MetS definitions have been established ${ }^{11,14,17,18)}$. The prevalence of MetS differs according to the criteria used for diagnosis ${ }^{19,20)}$. The MetS criteria by the Japanese Society of Internal Medicine stands at variance with others in the following respect: (i) increased WC is a prerequisite for MetS diagnosis, and (ii) TG and HDL-C are used in combination to define dyslipidemia, whereas TG and HDL-C are used separately in the other criteria. WC is measured according to population- and country-specific criteria, therefore, it is not surprising that different diagnostic rates are obtained in different racial groups even when using the same MetS definition. Although the positive relationship between high ferritin levels and MetS has been demonstrated by a metaanalysis ${ }^{10)}$, this study did not include Japanese people and the criteria used for MetS diagnosis were mainly those of NCEP ATP $\mathrm{III}^{11)}$. Therefore, the main strength of our study is that we demonstrated the association between elevated ferritin levels and MetS in Japanese men and women using the MetS criteria established specifically for Japanese people. Although we did not necessarily obtain statistically significant results in serum ferritin levels for all of the MetS components, ferritin is not considered inferior compared with the well-known marker hsCRP with respect to the association with MetS.

The normal ranges of serum ferritin used in the present study were $21.0-282.0 \mathrm{ng} / \mathrm{mL}$ for men, and $5.0-157.0 \mathrm{ng} / \mathrm{mL}$ for women. These normal ranges are probably established based on the 2.5th and 97.5th percentiles using reference individuals, and the upper limit does not mean the cutoff value is considered as a risk factor of MetS. WHO defines levels of ferritin that indicate severe iron overload as $>200 \mathrm{ng} / \mathrm{mL}$ for men and $>150 \mathrm{ng} / \mathrm{mL}$ for women ${ }^{21}$. There are several studies which compared the lowest and the highest quartiles of ferritin levels, and the highest quartile values lay between 194-423 for men and 94-231 for women $^{22-29)}$. In our subjects with MetS, average ferritin values were $213.8 \pm 137.6 \mathrm{ng} / \mathrm{mL}$ for men and $126.3 \pm 88.4 \mathrm{ng} / \mathrm{mL}$ for women, which is in accord with previously published data. Our study as well as most of the other studies did not distinguish premenopausal women from postmenopausal women. In only one study $^{22)}$, premenopausal and postmenopausal women were analyzed separately, and it was reported that the values of ferritin that were associated with metabolic syndrome were $89 \mathrm{ng} / \mathrm{mL}$ in premenopausal and $212 \mathrm{ng} / \mathrm{mL}$ in postmenopausal women because of iron losses by menstruation in premenopausal women. The positive correlation between ferritin and age observed in our female subjects may be for this reason. However, because we do not have information about menstruation, we could not distinguish premenopausal women from postmenopausal women, which is one of the limitations of this study.

The mechanisms of the effect of elevated ferritin on metabolic disorders are not fully understood. Chronic inflammation in adipose tissue plays an important part in the pathophysiology of $\mathrm{MetS}^{12)}$, and increased ferritin may reflect the inflammatory component of MetS. Iron may catalyze the formation of free radicals and cause oxidative stress ${ }^{29}$. HsCRP is also a marker of inflammation, and is widely used for predicting cardiovascular risks in MetS. Therefore, we examined the association of ferritin and MetS in comparison with that of hsCRP and MetS in this study. In addition to inflammation, it was recently reported that iron regulates adiponectin and insulin sensitivity, which can well modulate the MetS condition. Gabrielsen et al. found that mice fed a high-iron diet and cultured adipocytes treated with iron exhibited decreased adiponectin mRNA and protein, iron negatively regulated adiponectin transcription via FOXO1-mediated repression using 3T3-L1 cells, and loss of the adipocyte iron export channel, ferroportin, in mice resulted in adipocyte iron loading, decreased adiponectin, and insulin resistance ${ }^{13)}$. They also demonstrated in humans that ferritin was increased and adiponectin was decreased in type 2 diabetic and in obese diabetic subjects compared with those in equally obese individuals without metabolic syndrome ${ }^{13)}$. More interestingly, they found that phlebotomy of humans with impaired glucose tolerance and ferritin values in the highest quartile of normal increased adiponectin and improved glucose tolerance ${ }^{13)}$. These findings demonstrate a causal role for iron as a risk factor for metabolic syndrome and a role for adipocytes in modulating metabolism through adiponectin in response to iron stores.

There were some limitations in the present study. First, the interpretation of ferritin values may become difficult in the presence of malnutrition causing iron deficiency, infection, inflammation or liver diseases. Our subjects who undergo anti-aging health checks at Tokai University Tokyo Hospital are considered to be more wealthy and health-conscious than ordinary people, and there is little likelihood that they are in such severe condition. Second, we could not distinguish people on medication for hypertension, dyslipidemia, or diabetes from those without treatment. Third, because of the cross-sectional nature of the study, the cause-effect relationship of our findings is uncertain. Finally, we simply carried out univariate analysis between ferritin and the clinical parameters. Further investigations are necessary to examine the interrelations and also to elucidate the causal relationships among these factors.

In conclusion, the present study shows that serum ferritin increased in proportion to the number of MetS components and was significantly higher in MetS subjects than in non-MetS counterparts in Japanese men and women. Ferritin is involved in the 
occurrence of oxidative stress and regulation of adiponectin, both of which can modulate the MetS condition. High serum ferritin concentrations could potentially be used as a biomarker for MetS as well as hsCRP.

\section{ACKNOWLEDGEMENTS}

This study was supported, in part, by a Grant-in-Aid for Scientific Research (C) to YN (25350855) from the Ministry of Education, Culture, Sports, Science and Technology, Japan.

The authors state that they have no Conflict of Interest (COI).

\section{REFERENCES}

1) Fernández-Real JM, López-Bermejo A, Ricart W. Cross-talk between iron metabolism and diabetes. Diabetes 2002; 51: 234854.

2) Ford ES, Cogswell ME. Diabetes and serum ferritin concentration among U.S. adults. Diabetes Care 1999; 22: 1978-83.

3) Forouhi NG, Harding AH, Allison M, Sandhu MS, Welch A, Luben R, et al. Elevated serum ferritin levels predict new-onset type 2 diabetes: results from the EPIC-Norfolk prospective study. Diabetologia 2007; 50: 949-56.

4) Jiang R, Manson JE, Meigs JB, Ma J, Rifai N, Hu FB. Body iron stores in relation to risk of type 2 diabetes in apparently healthy women. JAMA 2004; 291: 711-7.

5) Mojiminiyi OA, Marouf R, Abdella NA. Body iron stores in relation to the metabolic syndrome, glycemic control and complications in female patients with type 2 diabetes. Nutr Metab Cardiovasc Dis 2008; 18: 559-66.

6) Piperno A, Trombini P, Gelosa M, Mauri V, Pecci V, Vergani A, et al. Increased serum ferritin is common in men with essential hypertension. J Hypertens 2002; 20: 1513-8.

7) Halle M, König D, Berg A, Keul J, Baumstark MW. Relationship of serum ferritin concentrations with metabolic cardiovascular risk factors in men without evidence for coronary artery disease. Atherosclerosis 1997; 128: 235-40.

8) Williams MJ, Poulton R, Williams S. Relationship of serum ferritin with cardiovascular risk factors and inflammation in young men and women. Atherosclerosis 2002; 165: 179-84.

9) Gillum RF. Association of serum ferritin and indices of body fat distribution and obesity in Mexican American men - the Third National Health and Nutrition Examination Survey. Int J Obes Relat Metab Disord 2001; 25: 639-45.

10) Abril-Ulloa V, Flores-Mateo G, Solà-Alberich R, Manuel-yKeenoy B, Arija V. Ferritin levels and risk of metabolic syndrome: meta-analysis of observational studies. BMC Public Health 2014; 14: 483. doi: 10.1186/1471-2458-14-483. (Accessed February 2, 2016, at http://bmcpublichealth.biomedcentral.com/ articles/10.1186/1471-2458-14-483).

11) Expert Panel on Detection, Evaluation, and Treatment of High Blood Cholesterol in Adults. Executive Summary of the Third Report of the National Cholesterol Education Program (NCEP) Expert Panel on Detection, Evaluation, and Treatment of High Blood Cholesterol in Adults (Adult Treatment Panel III). JAMA 2001; 285: 2486-97.

12) Hotamisligil GS. Inflammation and metabolic disorders. Nature 14 2006; 444: 860-7.

13) Gabrielsen JS, Gao Y, Simcox JA, Huang J, Thorup D, Jones D, et al. Adipocyte iron regulates adiponectin and insulin sensitivity. J Clin Invest 2012; 122: 3529-40.
14) Committee for Japanese Definition of Metabolic Syndrome. Definition and criteria of metabolic syndrome. J Jpn Soc Int Med 2005; 94: 794-809 (in Japanese).

15) Nishizaki Y, Kubo A, Kuwahira I, et al. Anti-aging health checkup system - For the prevention of potentially progress aging related disadvantageous changes in elderly. Health Evaluation and Promotion 2012; 39: 549-57.

16) Alberti KG, Zimmet PZ. Definition, diagnosis and classification of diabetes mellitus and its complications. Part 1: diagnosis and classification of diabetes mellitus. Provisional report of a WHO consultation. Diabet Med 1998; 15: 539-53.

17) Alberti KG, Zimmet P, Shaw J. Metabolic syndrome: a new world-wide definition. A consensus statement from the International Diabetes Federation. Diabet Med 2006; 23: 469-80.

18) Alberti KG, Eckel RH, Grundy SM, Zimmet PZ, Cleeman JI, Donato KA, et al. Harmonizing the metabolic syndrome: a joint interim statement of the International Diabetes Federation Task Force on Epidemiology and Prevention; National Heart, Lung, and Blood Institute; American Heart Association; World Heart Federation; International Atherosclerosis Society; and International Association for the Study of Obesity. Circulation 2009; 120: $1640-5$.

19) Kahn R, Buse J, Ferrannini E, Stern M. American Diabetes Association; European Association for the Study of Diabetes. The metabolic syndrome: time for a critical appraisal: joint statement from the American Diabetes Association and the European Association for the Study of Diabetes. Diabetes Care 2005; 28: 2289304.

20) Oda E, Abe M, Veeraveedu PT, Watanabe K. Considerable disagreement among definitions of metabolic syndrome for Japanese. Circ J 2007; 71: 1239-43.

21) WHO. Serum ferritin concentrations for the assessment of iron status and iron deficiency in populations. Vitamin and Mineral Nutrition Information System. Geneva, World Health Organization, 2011 (WHO/NMH/NHD/MNM/11.2). (Accessed January 7, 2016, at http://www.who.int/vmnis/indicators/serum_ferritin.pdf).

22) Jehn M, Clark JM, Guallar E. Serum ferritin and risk of the metabolic syndrome in U.S. adults. Diabetes Care 2004; 27: 2422-8.

23) Shi Z, Hu X, Yuan B, Hu G, Pan X, Holmboe-Ottesen G. Coexistence of anaemia and the metabolic syndrome in adults in Jiangsu, China. Asia Pac J Clin Nutr 2008; 17: 505-13.

24) Sun L, Franco OH, Hu FB, Cai L, Yu Z, Li H, et al. Ferritin concentrations, metabolic syndrome, and type 2 diabetes in middleaged and elderly Chinese. J Clin Endocrinol Metab 2008; 93: 4690-6.

25) Ryu SY, Kim KS, Park J, Kang MG, Han MA. Serum ferritin and risk of the metabolic syndrome in some Korean rural residents. J Prev Med Public Health 2008; 41: 115-20.

26) Kang HT, Linton JA, Shim JY. Serum ferritin level is associated with the prevalence of metabolic syndrome in Korean adults: the 2007-2008 Korean National Health and Nutrition Examination Survey. Clin Chim Acta 2012; 413: 636-41.

27) Hamalainen $P$, Saltevo J, Kautiainen H, Mantyselka P, Vanhala M. Erythropoietin, ferritin, haptoglobin, hemoglobin and transferrin receptor in metabolic syndrome: a case control study. Cardiovasc Diabetol; 11:116. doi: 10.1186/1475-2840-11-116,2012. (Accessed February 2, 2016, at http://cardiab.biomedcentral.com/articles/ 10.1186/1475-2840-11-116).

28) Li J, Wang R, Luo D, Li S, Xiao C. Association between serum ferritin levels and risk of the metabolic syndrome in Chinese adults: a population study. PLoS One 2013; 8: e74168.

29) Reif DW. Ferritin as a source of iron for oxidative damage. Free Radic Biol Med 1992; 12: 417-27. 